\title{
Comparative Study between the Elastic Nail versus Hip Spica Cast in Early Treatment of Pediatric Femoral Shaft Fractures
}

\author{
Rebar M. Noori Khaffaf ${ }^{1,2}$, Abbas Hasan Altaweel1,2 \\ ${ }^{1}$ Department of Orthopedic, Sulaimani School of Medicine, KRG, Iraq \\ ${ }^{2} \mathrm{Al}$ Kafeel Private Hospital, Kerbala, Iraq \\ Email: rebarkhaffaf@gmail.com
}

How to cite this paper: Khaffaf, R.M.N. and Altaweel, A.H. (2016) Comparative Study between the Elastic Nail versus Hip Spica Cast in Early Treatment of Pediatric Femoral Shaft Fractures. Open Journal of Orthopedics, 6, 259-267.

http://dx.doi.org/10.4236/ojo.2016.69034

Received: June 23, 2016

Accepted: August 29, 2016

Published: September 1, 2016

Copyright $\odot 2016$ by authors and Scientific Research Publishing Inc. This work is licensed under the Creative Commons Attribution International License (CC BY 4.0).

http://creativecommons.org/licenses/by/4.0/ (c) (i) Open Access

\section{Abstract}

Introduction: Femoral shaft fractures are among the most common pediatric injury, which have the highest incidence among other pediatric fractures, and treatment of them carries a lot of controversies. Aim of the study: To compare the outcome of fixation of femoral shaft fracture by elastic nail with Spica cast. Patient and method: This prospective comparative study was carried out in Sulaimani Teaching Hospital, in the period from the $10^{\text {th }}$ of December 2011 to the $10^{\text {th }}$ of June 2012, for two groups of children whose ages were between 4 - 12 years (average 6.61 years), sustained traumatic femoral shaft fractures with follow-up period of about 6 months. The first group was consisting of 30 children treated by Elastic Intramedullary Nail, while the second group was consisted of 30 children treated by hip Spica. The selection was made on random bases. Results: Age range was between $4-12$ years and showed male predominance in both groups with ratio of about 2:1 while fracture site showed predominance of the midshaft pattern in both groups. This study showed highly significant deference ( $P$ value of 0.001 ) between the two groups (Spica group of 3 days versus Nail group median of rate 4.5 days) in the admission period. Our sample showed shortening of about $2 \mathrm{~cm}$ in 2 case in the Nail group (6.7\%) versus 6 cases (20\%) in Spica group. We reported 4 cases of wound infection (13.3\%) and 4 cases of pin site irritation (13.3\%) in nail group. A higher rate of malunion was observed in the Spica group (10 cases more than $10^{\circ}$ angulation in coronal plane) while the Nail group reported 2 case more than $10^{\circ}$ in coronal plane. The mean operative time for Nail group was 55 minutes while in Spica group was 30 minutes. We reported shorter time to start mobilization and walking with support or independently in the nail group (weight bearing time 7.2 weeks) compared with the Spica casting group (weight bearing time 7.5 weeks). Conclusion: Elastic nail fixation yields better outcome for femoral shaft fracture in form of easier child handling, parent's satisfaction, and main- 
taining acceptable fracture alignment.

\section{Keywords}

Femoral Shaft Fractures, Elastic Nails, Hip Spica

\section{Introduction}

Femoral-shaft fractures are among the most common fractures of the lower extremity in children, with an annual incidence of up to 1 per 5000 in United States [1] [2], unfortunately, we couldn't find any statistical data about the incidence in Iraq or Kurdistan region. Elastic nailing (EN) is commonly used to stabilize femoral fractures in the school-aged children [1].

This prospective randomized controlled study compares the outcome of the Elastic nail with Spica cast in treating femoral fractures in children in terms of recovery and complications and nursing difficulties. Several techniques are now available for their treatment. The type and location of the fracture, the degree of comminution, the age of the patient, the patient's social and economic demands, all these factors determine the type of implant used for surgery.

Risk factors suggested to be associated with complications of flexible nailing include [3]-[6]:

1) Age older than 10 or 11 years and weight exceeding $49 \mathrm{~kg}$.

2) Obesity, related to wound site complications or failure at the fracture site $(40 \%$ complication rate in obese children).

3) Subtrochanteric fractures.

4) Comminution, more than $25 \%$ of shaft.

5) Open fractures.

6) Multiple injuries.

In addition, malunions are more frequent with flexible titanium nails than steel counterpart.

\section{Patient and Method}

This prospective comparative study was carried out in Sulaimani Teaching Hospital in the period from the $10^{\text {th }}$ of December 2011 to the $10^{\text {th }}$ of June 2012 for two groups of children whose ages were between 4 - 12 years (average 6.61 years) sustaining traumatic femoral shaft fractures with follow up period of about 6 months. The first group consisted of 30 children treated by Elastic Intramedullary Nailing and the nails were either steel or titanium. While the second Group consisted of 30 children treated by Hip Spica, selections were made on random basis using computer randomization system.

Only those patients with diaphysial fractures (a transverse, oblique, spiral fractures) with no other associated fractures of the lower limb or neurovascular injury.

Patients with intra articular fracture, polytrauma patients and those who failed to 
respond to conservative treatment, were excluded from the study. All patients admitted to emergency department, with a complete history and physical examination. Ethical approval was obtained from the Institutional Review Board of Sulaimani University hospital. Informed consent was obtained from both parents prior to the procedure; though some parents understood the right of voluntary participation and withdrawal from the trial. Selection of the patient was made after discussion with their families about the possibility of failure of conservative treatment and possible conversion for internal fixation later on. After those informed consents were taken from the parents about the anesthesia, the approach type and the possible complications, every patient receive preliminary treatment at admission time consisted of prophylactic antibiotics, analgesia and skin traction.

For those patients who selected for surgery the surgeries were performed under general anesthesia with the patients on the fracture table in supine position (Figure 1(a)). The diameter of the individual nail was selected according to Flynn et al. formula [1] [2] [5] [7] (Diameter of nail $=$ Width of the narrowest point of the medullary canal on Anteroposterior and Lateral view $\times 0.4 \mathrm{~mm}$ ) [8] and intraoperative assessment. The diameter of the nail was chosen so that each nail occupies at least one-third to $40 \%$ of

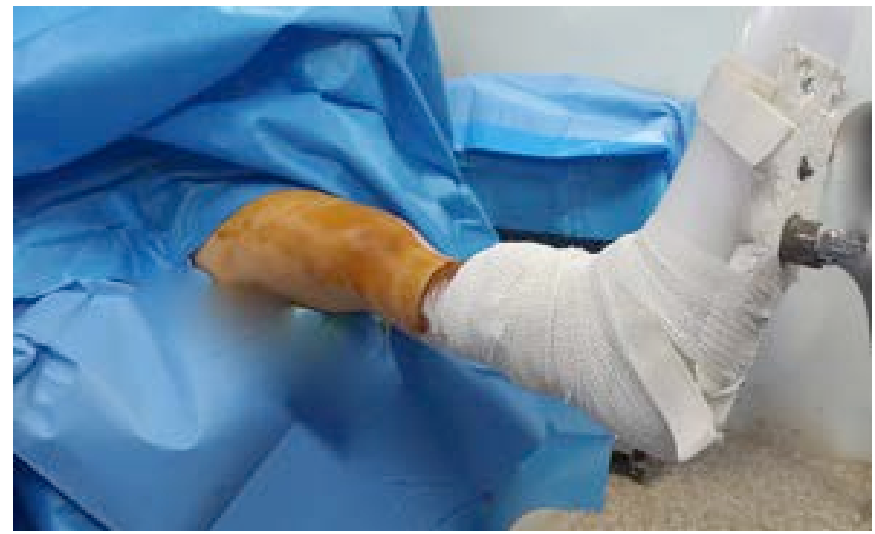

(a)

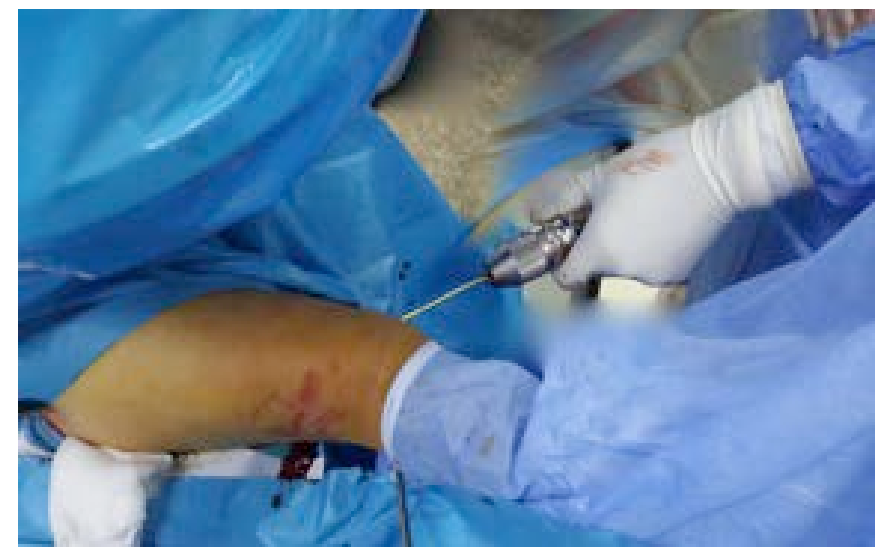

(c)

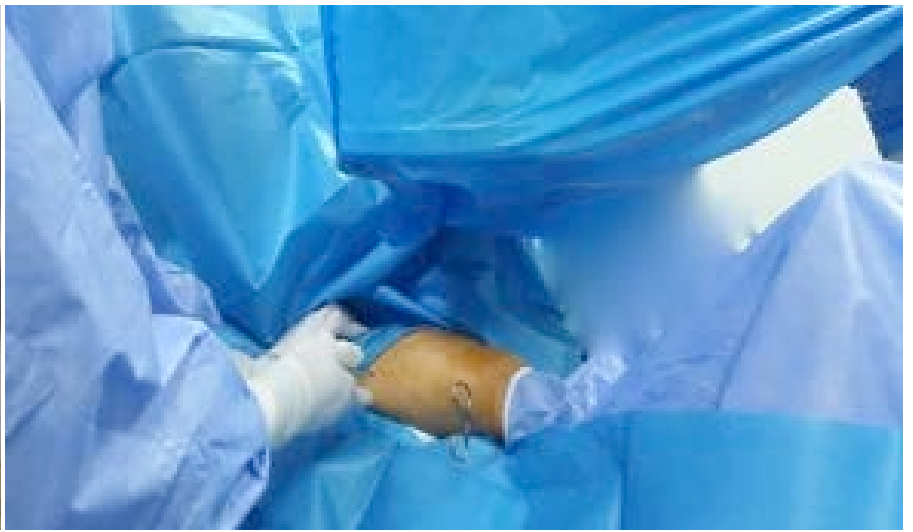

(b)

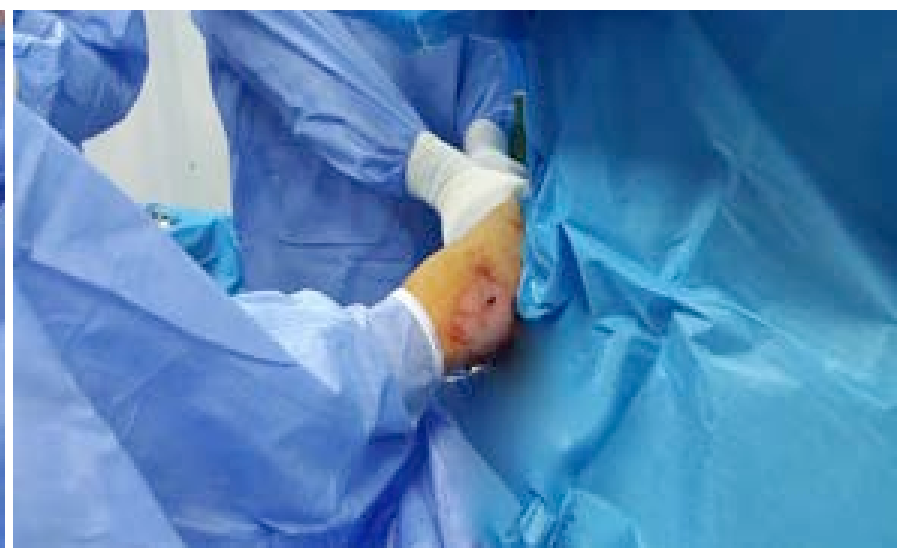

(d)

Figure 1. (a) Preparation on the traction table; (b) localization of the entry point on the C-arm; (c) introduction of the elastic nails; (d) site of entry. 
the medullary cavity. Fractures were reduced using fluoroscopic guidance. Nails inserted in retrograde or antigrade fashion with medial and lateral incision $2.5-3.5 \mathrm{~cm}$ above the phys are Figures 1(b)-(d). The nails were pre bent sufficiently so that apex of the bowed nails rested at the same level on the fracture site to ensure a good equal recoil force.

Open reduction was required in three cases due to soft tissue interposition and five surgeries were done without orthopedic table and. The median duration of surgery for nailing was 55 minutes (40 - $70 \mathrm{~min}$ ). Radiological union was achieved in a mean time of 4.7 weeks (Figures 2(a)-(d)).

Postoperatively patients were nursed in supine position with the operated side elevated on a pillow. Patients were mobilized without weight bearing on the fifth to seventh day postoperatively. Follow up schedule were made on two weekly basis visit for the first 6 weeks and later on monthly after that Partial weight bearing was started at three weeks and full weight bearing by six to eight weeks depending on the fracture configuration and callus response.

Surgeries of the Spica group were also undertaken under GA and long leg cast were applied in slight abduction by aid of Spica Saddle box with manipulation in manner keeping the hips in 45 degree of flexion and about 40 degree abduction and the knee in slight flexion (20 - 30 degrees). Anterior superior iliac spine, patella and $2^{\text {nd }}$ toe aligned in one straight line as a crude assessment. Padding of the bony prominences and the genitalia were made to avoid maceration and sores. The median duration of surgery was 30 minutes. Radiological union was achieved in a mean time of 5.4 weeks.

Postoperative follow up first was weekly for 2 weeks then every two weeks till fracture consolidation (8 - 12 weeks) and then monthly intervals till patient can walk with full weight bearing and every visits patients were clinically and radio logically evaluated and at 6 months the final results were evaluated using criteria of Flynn et al. [2] [8] (Tables 1-3, Figure 3(a), Figure 3(b)).

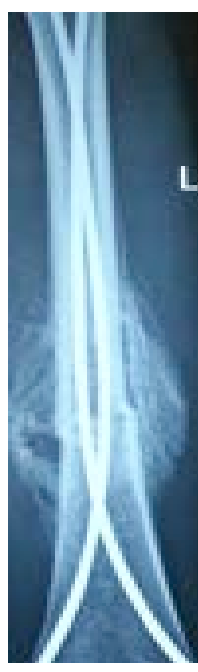

(a)

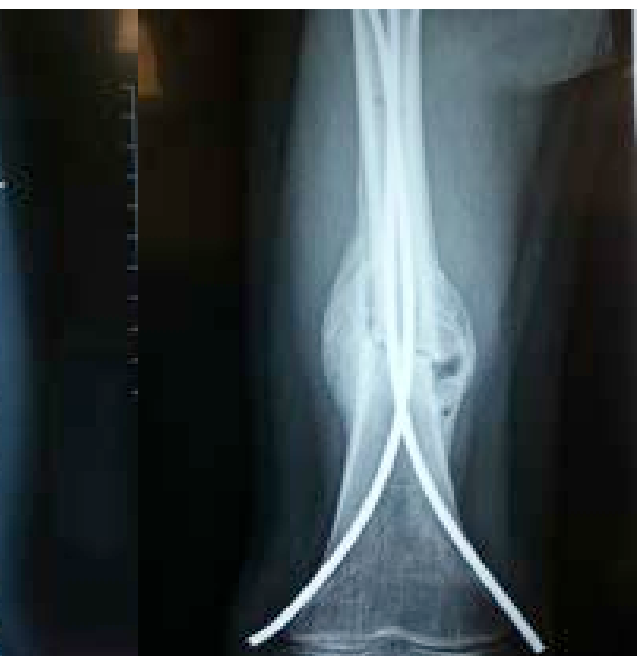

(b)

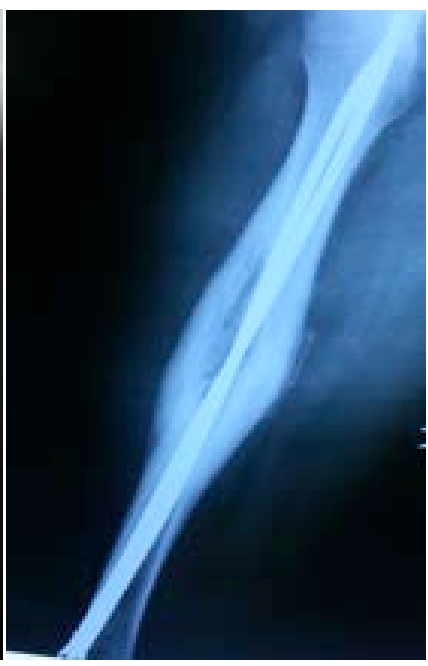

(c)

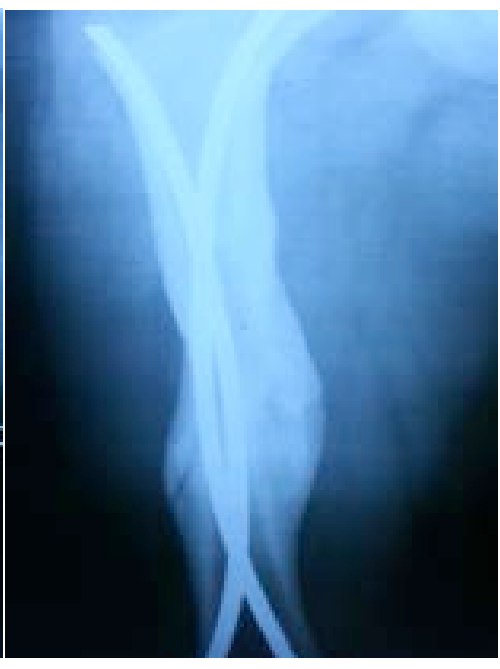

(d)

Figure 2. This figure shows (a) (b) fracture callus after 3 weeks from the surgery, (c) (d) consolidation after 6 months. 


\section{Results}

(32 cases) $53.3 \%$ of the cases were right sided fracture while the rest (47\%) were left sided, the most common fracture location was at the middle third (34) case (56.6\%), while the most common pattern was oblique (28) cases (46.6\%) (Table 1), shortening more than $2 \mathrm{~cm}$ reported only in (2) cases in the Nail group while there was (6) cases $20 \%$ in the Spica group. There were 4 cases of superficial wound infection in the nail group, no deep infection was reported in the both group, 2 cases of nail migration were reported, mal alignment of more than 10 degree were found in (2) cases In the Nail

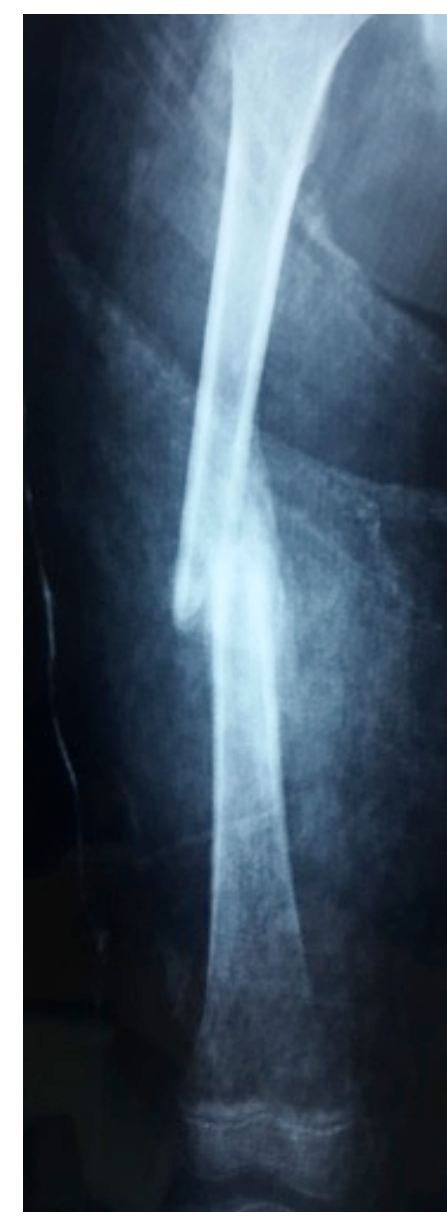

(a)

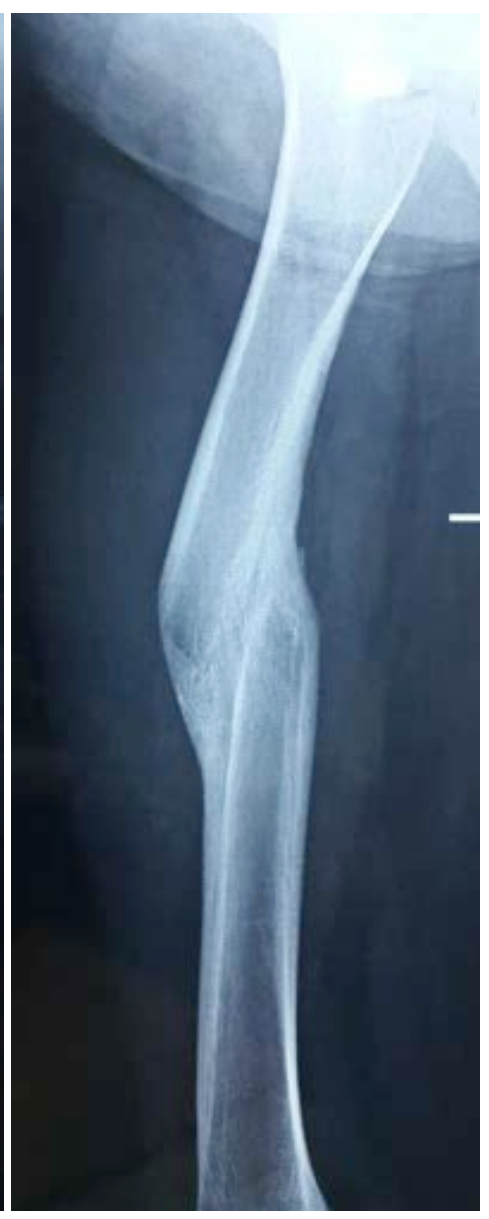

(b)

Figure 3. This figure shows (a) mid shaft fracture treated by Spica with acceptable alignment with fair callus after 3 weeks, (b) at 6 months from the onset.

Table 1. This table shows Flynn's table.

\begin{tabular}{cccc}
\hline & Excellent & Good & Poor \\
\hline Limb length discripancy & $<1 \mathrm{~cm}$ & $<2 \mathrm{~cm}$ & $>2 \mathrm{~cm}$ \\
Angulation in degrees & $<5$ & $5-10$ & $>10$ \\
Pain & Absent & Absent & present \\
Complications & Absent & Mild & Major/extended morbidity
\end{tabular}


Table 2. This table shows the final results of the nail group.

\begin{tabular}{cccc}
\hline Parameters & Excellent & Good & Poor \\
\hline \multirow{2}{*}{ Limb length discrepancy } & $<1 \mathrm{~cm}$ & $<2 \mathrm{~cm}$ & $>2 \mathrm{~cm}$ \\
& 20 patients & 8 patients & 2 patients \\
Malalignment & $<5^{0}$ & $5^{0}-10^{\circ}$ & $>10^{0}$ \\
& 22 patients & 6 patients & 2 patients \\
Pain & Absent & Absent & Present \\
& ----- & ------ & ----- \\
Compilications & Absent & Mild & Major/extended morbidity \\
Mean & 18 & 12 & 0 \\
Percentage & 20 & 8.6 & 2 \\
\hline
\end{tabular}

Table 3. This table shows the final results of Spica group.

\begin{tabular}{cccc}
\hline Parameters & Excellent & Good & Poor \\
\hline \multirow{2}{*}{ Limb length discrepancy } & $<1 \mathrm{~cm}$ & $<2 \mathrm{~cm}$ & $>2 \mathrm{~cm}$ \\
& 20 patients & 8 patients & 2 patients \\
Malalignment & $<5^{0}$ & $5^{0}-10^{0}$ & $>10^{0}$ \\
& 22 patients & 6 patients & 2 patients \\
Pain & Absent & Absent & Present \\
& ------ & ------ & ---- \\
Compilications & Absent & Mild & Major/extended morbidity \\
Mean & 18 & 12 & 0 \\
Percentage & 20 & 8.6 & 2 \\
\hline
\end{tabular}

group. While there were (10) cases in the Spica group, no mal alignment in the sagittal plane more than 10 degree were reported in both group (Table 4).

The choice of treatment of femoral shaft fracture has remained a constant challenge to the orthopedic surgeons. Spica cast immobilization is a simple, effective and safe treatment for a femoral shaft fracture in children [8] [9]. It remains universally used, but is especially suited for children under the age of 5 years [6], when there is still significant potential for remodeling and the relatively light weight of child allows easy carrying and transfer [2]. The AAOS (American Academy of Orthopedic Surgeons) Clinical practice Guideline for the treatment of pediatric diaphyseal femur fracture suggests early Spica casting or traction with delayed Spica casting in children aged 6 months to 5 years [6]. However, to avoid the effects of prolonged Spica immobilization and to minimize abstinence from school programs and for better nursing careand avoiding skin macerations, the operative approach has been gaining popularity for the last two decades [10].

Elastic nail has the advantage over other implants particularly in this age group because it is simple, is a load-sharing internal splint that doesn't violate open phys is, allows early mobilization and maintains alignment [4] [11] [12].

Our study showed male predominance in both groups and this was comparable to the studies published by Shemshaki H. R. et al. [2], Saseendar S. et al. [3] and Jauquier N. et al. [6]. 
Table 4. This table shows the variable related to the fracture pattern in both groups.

\begin{tabular}{|c|c|c|}
\hline \multirow{2}{*}{ Variables related to the fracture } & \multicolumn{2}{|c|}{ Number and percentages } \\
\hline & Nail group & Spica group \\
\hline \multicolumn{3}{|l|}{ Side of fracture } \\
\hline Right & $16(53.3 \%)$ & $16(53.3)$ \\
\hline Left & $14(46.7 \%)$ & $14(46.7)$ \\
\hline \multicolumn{3}{|l|}{ Site of Fracture } \\
\hline Proximal $1 / 3$ & $12(40.0)$ & $16(53.3)$ \\
\hline Middle $1 / 3$ & $18(60.0)$ & $14(46.7 .0)$ \\
\hline \multicolumn{3}{|l|}{ Mechanism of Injury } \\
\hline FFH & $10(33.3)$ & $14(53.3 \%)$ \\
\hline RTA & $18(60.0)$ & $16(47.7)$ \\
\hline Others & $2(6.7)$ & \\
\hline \multicolumn{3}{|l|}{ Shape of Fracture } \\
\hline Transverse & $8(26.7)$ & $14(46.6 \%)$ \\
\hline Oblique & $14(46.7)$ & $12(40 \%)$ \\
\hline Spiral & $8(26.7$ & $4(13.3)$ \\
\hline & \multicolumn{2}{|c|}{ Numbers (percentages) } \\
\hline Complications of both groups & Nail & Spica \\
\hline \multicolumn{3}{|l|}{ Mal alignment (coronal plane) } \\
\hline Less than 5 degrees & $22(73.3 \%)$ & $12(40 \%)$ \\
\hline $5-10$ degrees & $6(20.0 \%)$ & $8(26.6)$ \\
\hline More than 10 degrees & $2(6.7 \%)$ & $10(33,3)$ \\
\hline \multicolumn{3}{|l|}{ Leg length discrepancies } \\
\hline More than $2 \mathrm{~cm}$ & $2(6.7)$ & $16(53.3 \%)$ \\
\hline $1-2 \mathrm{~cm}$ & $8(26.7)$ & $8(26.6 \%)$ \\
\hline Less than $1 \mathrm{~cm}$ or not present & $20(66.7)$ & $6(20 \%)$ \\
\hline \multicolumn{3}{|l|}{ Admission time } \\
\hline 2 days & $14(46.7 \%)$ & $2(6.7 \%)$ \\
\hline 3 days & $4(13.3 \%)$ & $8(26.7 \%)$ \\
\hline 4 days & & $6(20.0 \%)$ \\
\hline 5 days & & $6(20.0 \%)$ \\
\hline 6 days & & $4(13.3 \%)$ \\
\hline 7 days & & $4(13.3 \%)$ \\
\hline \multicolumn{3}{|l|}{ Plaster sores } \\
\hline Not Present & & $22(73.3 \%)$ \\
\hline Present & & $8(26.7 \%)$ \\
\hline \multicolumn{3}{|l|}{ Nursing difficulty and family } \\
\hline \multicolumn{3}{|l|}{ complains } \\
\hline Not Present & $28(93.3 \%)$ & $6(20.0 \%)$ \\
\hline Present & $2(6.7 \%)$ & $24(80.0 \%)$ \\
\hline \multicolumn{3}{|c|}{ Re applying due to loosening or re displacement } \\
\hline Not present & & $26(86.7 \%)$ \\
\hline Present & & $4(13.3 \%)$ \\
\hline Pin site irritation and perforation & $4(13.3 \%)$ & \\
\hline Wound infection & $4(13.3 \%)$ & \\
\hline
\end{tabular}


Regarding fracture site, our study showed middle third predominance in both groups and this is comparable with the studies published by Shemshaki et al. [2], Jauquier N. et al. [3] and Nicolas Lutz et al. [4]. Our study sample showed highly significant. deference (0.001) between 2 groups in admission time. Spica group in median of (3) days and for the Nail group in a median of 4.5 days was reported and this is comparable with the studies published by Shemshaki et al. [2], Saseendar S. et al. [3] and Jauquier N. et al. [4].

Shortening of $2 \mathrm{~cm}$ was reported in the fractured side in 2 cases in nail group (6.7\%), while in Spica group 6 cases were reported (20\%) which was statically non-significant difference and this may be due to small sample size and this was comparable with Saseendar S. et al., while Jauquier N. et al. shows significant discrepancy in Spica group that is may be due to 1 year follow up in their study.

There were 4 cases of wound infection (13.3\%) in nail group and they were superficial infection treated by oral Antibiotics and this was comparable to Shemshaki et al., while other studies didn't report any case of infection.

Our study reported 4 cases of pin site irritation and pain (13.3\%) in nail group this was higher than the result of Moroz L. A. et al. [10] study who reported 4 cases out of 234 cases $(1.7 \%)$ and that difference probably because of the miscalculation of the nail length, although in two of them nail migration happened in because of fracture pattern (short oblique).

Mal alignment assessment done in coronal and sagittal plane, we excluded rotational malalignment because difficulty to get proper image, a higher rate of malunion was observed in the Spica group (10 cases more than $10^{\circ}$ ) in coronal plane compared with the Nail group ( 2 case more than $10^{\circ}$ ). Deformities of more than 10 degrees in sagittal plane were not recorded This finding compatible to the results of Saseendar S. et al. while the Jauquier N. et al. didn't record any case.

Themean operative time for nail group was 55 minutes while in Spica group was 30 minutes, although we couldn't find any comparable result in other studies but we can relate that to usual preparation for every invasive surgery.

Our findings showed shorter time to start mobilization and walking with support or independently and sooner return to school in the nail group (weight bearing time 7.2 weeks) compared with the Spica casting group (weight bearing time 7.5 weeks) $(\mathrm{P}=0.449$ ). Shemshaki et al and Saseendar S. et al. have also showed such earlier recovery milestones.

Family complains and parent dissatisfaction about nursing difficulties, child movement and hygienic issues related to napkin application was found in 6 cases.

\section{Conclusions}

Based on our statistics, elastic nail fixation method yields better outcome for femoral shaft fractures in form of maintaining better alignment, earlier weight bearing, easier nursing and handling, although it has the drawback of possible infection and pin site irritation. So that we recommend elastic nail for children with age greater than 5 years old because of easy care and early rehabilitation, it is more hygienic to the child, we also recommend the use of orthopedic table and (F) tool as a amendatory facility to shorten operative time, after insertion of the elastic nail, we recommend release of traction and 
10 cycles of flexion and extension of the knee to allow collapse of the fracture before making the final nail cut to avoid the problem related to nail migration.

We acknowledge that our follow-up period was short and our sample size was relatively small, so we recommend longer follow-up period and bigger sample size.

\section{References}

[1] Hinton, R.Y., Lincoln, A., Crockett, M.M., Sponseller, P. and Smith, G. (1999) Fractures of the Femoral Shaft in Children. Incidence, Mechanisms, and Sociodemographic Risk Factors. Journal of Bone and Joint Surgery (American), 81, 500-509.

[2] Shemshaki, H.R., Mousavi, H., Salehi, G. and Eshaghi, M.A. (2011) Titanium Elastic Nailing versus Hip Spica Cast in Treatment of Femoral-Shaft Fractures in Children. Journal of Orthopaedics and Traumatology, 12, 45-48. http://dx.doi.org/10.1007/s10195-011-0128-0

[3] Nayagam, S. (2010) Injuries of the Hip and Femur. In: Solomon, L., Warwick, D. and Nayagam, S., Eds., Apley's System of Orthopedics and Fractures, Chap. 29, 9th Edition, Hodder Arnold, London, 859.

[4] James, H. (2013) Fractures and Dislocation in Children. In: Terrycanal, S. and James, H., Eds., Campbell s Operative Orthopaedics, Chap. 36, 12th Edition. Mosb, Philadelphia, 978-989.

[5] Green, J.K., Werner, F.W., Dhawan, R., Evans, P.J., Kelley, S. and Webster, D.A. (2005) A Biomechanical Study on Flexible Intramedullary Nails Used to Treat Pediatric Femoral Fractures. Journal of Orthopaedic Research, 23, 1315-1320.

http://dx.doi.org/10.1016/j.orthres.2005.04.007

[6] Jauquier, N., Doerfler, M., Haecker, F.M., Hasler, C., Zambelli, P.Y. and Lutz, N. (2010) Immediate Hip Spica Is as Effective as, but More Efficient Than, Flexible Intramedullary Nailing for Femoral Shaft Fractures in Pre-School Children. Journal of Children's Orthopaedics, 4, 461-465. http://dx.doi.org/10.1007/s11832-010-0279-1

[7] Narayanan, U.G., Hyman, J.E., Wainwright, A.M., et al. (2004) Complications of Elastic Stable Intramedullary Nail Fixation of Pediatric Femoral Fractures, and How to Avoid Them. Journal of Pediatric Orthopaedics, 24, 363. http://dx.doi.org/10.1097/01241398-200407000-00004

[8] Flynn, J.M., Luedtke, L.M., Ganley, T.J., Dawson, J., Davidson, R.S., Dormans, J.P., et al. (2004) Comparison of Titanium Elastic Nails with Traction and a Spica Cast to Treat Femoral Fractures in Children. Journal of Bone and Joint Surgery(American), 86-A, 770-777.

[9] Buehler, K.C., Thompson, J.D., Sponseller, P.D., Black, B.E., Buckley, S.L. and Griffin, P.P. (1995) A Prospective Study of Early Spica Casting Outcomes in the Treatment of Femoral Shaft Fractures in Children. Journal of Pediatric Orthopaedics, 15, 30-35.

http://dx.doi.org/10.1097/01241398-199501000-00008

[10] Moroz, L.A., Launay, F., Kocher, M.S., Newton, P.O., Frick, S.L., Sponseller, P.D. and Flynn, J.M. (2006) Titanium Elastic Nailing of Fractures of the Femur in Children. Predictors of Complications and Poor Outcome. Journal of Bone and Joint Surgery (British), 88, 1361-1366. http://dx.doi.org/10.1302/0301-620X.88B10.17517

[11] Saikia, K.C., Bhuyan, S.K., Bhattacharya, T.D. and Saikia, S.P. (2007) Titanium Elastic Nailing in Femoral Diaphyseal Fractures of Children in 6-16 Years of Age. Indian Journal of Orthopaedics, 41, 381-385. http://dx.doi.org/10.4103/0019-5413.33876

[12] Cusick, L., Thompson, N.W., Taylor, T.C. and Cowie, G.H. (2005) Paediatric Femoral Fractures. Ulster Medical Journal, 74, 98-104. 
Submit or recommend next manuscript to SCIRP and we will provide best service for you:

Accepting pre-submission inquiries through Email, Facebook, LinkedIn, Twitter, etc. A wide selection of journals (inclusive of 9 subjects, more than 200 journals)

Providing 24-hour high-quality service

User-friendly online submission system

Fair and swift peer-review system

Efficient typesetting and proofreading procedure

Display of the result of downloads and visits, as well as the number of cited articles

Maximum dissemination of your research work

Submit your manuscript at: http://papersubmission.scirp.org/ 